\title{
The Effect of Dimethyl Dimethoxy Biphenyl Dicarboxylate (DDB) against Tamoxifen-induced Liver Injury in Rats: DDB Use Is Curative or Protective
}

\author{
Hesham A. El-Beshbishy* \\ Biochemistry Department, Faculty of Pharmacy (Boys), Al-Azhar University, Nasr City, Cairo, Egypt
}

Received 20 October 2004, Accepted 3 December 2004

\begin{abstract}
Tamoxifen citrate is an anti-estrogenic drug used for the treatment of breast cancer. It showed a degree of hepatic carcinogenesis, when it used for long term as it can decrease the hexose monophosphate shunt and thereby increasing the incidence of oxidative stress in liver rat cells leading to liver injury. In this study, a model of liver injury in female rats was done by intraperitoneal injection of tamoxifen in a dose of $45 \mathrm{mg} / \mathrm{kg}$ body weight for 7 successive days. This model produced a state of oxidative stress accompanied with liver injury as noticed by significant declines in the antioxidant enzymes (glutathione-Stransferase, glutathione peroxidase and catalase) and reduced glutathione concomitant with significant elevations in TBARS (thiobarbituric acid reactive substance) and liver transaminases; sGPT (serum glutamate pyruvate transaminase) and sGOT (serum glutamate oxaloacetate transaminase) levels. The oral administration of dimethyl dimethoxy biphenyl dicarboxylate (DDB) in a dose of 200 $\mathrm{mg} / \mathrm{kg}$ body weight daily for 10 successive days, resulted in alleviation of the oxidative stress status of tamoxifenintoxicated liver injury in rats as observed by significant increments in the antioxidant enzymes (glutathione-Stransferase, glutathione peroxidase and catalase) and reduced glutathione concomitant with significant decrements in TBARS and liver transaminases; sGPT and sGOT levels. The administration of DDB before tamoxifen intoxication (as protection) is more little effective than its curative effect against tamoxifen-induced liver injury. The data obtained from this study speculated that DDB can mediate its biochemical effects through the enhancement of the
\end{abstract}

Present Address: Chemistry Department, Faculty of Science, Taibah University, P.O. Box 344, Al-Madinah Al-Munawwarah, Saudi Arabia. Tel: 966-82-72-135

E-mail: Hesham_Elbeshbishy@hotmail.com

*To whom correspondence should be addressed.

Tel: 00966048272135

E-mail: hesham_elbeshbishy@hotmail.com antioxidant enzyme activities and reduced glutathione level as well as decreasing lipid peroxides.

Keywords: Dimethyl dimethoxy biphenyl dicarboxylate, Glutathione peroxidase, Glutathione-S-transferase, Reduced glutathione, Tamoxifen, Thiobarbituric acid reactive substance

\section{Introduction}

Tamoxifen citrate, 1-[4-(2-dimethyl-aminoethoxy)phenyl]-1,2diphenyl-1-butene), is a nonsteroidal antiestrogen drug that is used in the treatment and prevention of all stages of hormonedependent breast cancer (Desai et al., 2002; Jordan, 2003). Tamoxifen reduce the level of estrogen and estrogen receptor with no change in progesterone contents (Liu et al., 2004). This effect is mediated by the inhibition of the action of both $17 \beta$ estradiol and esterone (Yu and Bender, 2002; Stefano et al., 2003) and competition with estrogen for binding to its receptor (Ali and Coombes, 2002). Also, tamoxifen is able dramatically to inhibit the formation of $17 \beta$ estradiol and esterone epoxides as measured by both the loss of their ability to inhibit DNA-dependent RNA synthesis and to bind to nuclear DNA (Yu and Bender, 2002).

Tamoxifen is metabolized by human cytochrome P450s 3A4, 2C9, 2B6, 2C8, 2C19, 2D6, 1A1, 1A2, and 2A6 (Dehal and Kupfer, 1997, 1999) and is also an effective inducer of $\mathrm{P} 450 \mathrm{~s} 2 \mathrm{~B} 2,2 \mathrm{~B} 1$, and 3A in rat liver at doses comparable with the therapeutic doses used in humans (Emile et al., 1995). Kupfer et al., 1994 and Sridar et al., 2002, reported that, tamoxifen has been found to be metabolized by liver primarily into three metabolites, tamoxifen-N-oxide, formed by flavincontaining monooxygenase, and $\mathrm{N}$-desmethyl and 4hydroxytamoxifen, formed by cytochrome P450. The Ndemethylation was demonstrated to be catalyzed by $\mathrm{P} 4503 \mathrm{~A}$ in rat and human liver; however, the P450s catalyzing the 4hydroxylation have not been identified.

It was obvious that, certain toxicants (may be drug 
overdose or harmful substances) have been characterized by their ability to induce liver injury following the cleavage by cytochrome P450 to form free radicals (Rosen et al., 1999). Lipid peroxidation via substraction of hydrogen from unsaturated fatty acids forms carbon-centered lipid radicals (McCay et al., 1984). This molecule adds molecular oxygen to form lipid peroxy radicals, thereby initiating the process of lipid peroxidation (Letteron et al., 1990). It was revealed that, tamoxifen in high dose is a known liver carcinogen in rats (Ahotupa et al., 1994; Calballero et al., 2001) which is due to oxygen radical overproduction which occurs during tamoxifen metabolism. Oxidative DNA and lipid damage was detected by the measurement of DNA adduct and lipid peroxides, respectively (Pagano et al., 2001). Tamoxifen-DNA adducts have been detected in rats administered tamoxifen (Han and Liehr, 1992). On the other hand, tamoxifen has been shown to potentiate the nitrous oxide production in breast cancer patients through the enhancement of the nitric oxide synthase II expression (Simeone et al., 2002). This strong hepatocarcinogenic effect of tamoxifen in rats raises issues bearing on the prophylactic chronic administration to healthy women (Williams et al., 1993). Also, tamoxifen can exert some side effects such as hot flushes, nausea, hypertriglyceridemia and decreased HDL cholesterol (Saarto et al., 1996; Atalay et al., 2004).

Dimethyl dimethoxy biphenyl dicarboxylate (DDB) is a synthetic analogue of Schizandrin $\mathrm{C}$, one of compounds isolated from Fructus schizandrae, which is a traditional Chinese medicine (Kim et al., 1999). Although, Schizandrae have a long history of medicinal use within the traditional Chinese system, the world begun recently to understand its pharmacological possibilities and clinical applications. Experimental evidence suggests that DDB has hepatoprotective abilities and functions as a potent antioxidant and have proven clinically in the treatment of chronic viral and chemicallyinduced hepatitis (Liu, 1989; Fu and Liu, 1992; Ip et al., 2000). Decoctions of DDB were found to possess strong in vitro inhibitory action on Bacillus subtilis, Bacillus dysenteraie, Bacillus typhi and Staphylococcus aureus (Hong, 1986). So that, it is indicated in cases of chronic cough and dyspnea, diarrhea, night sweats, wasting disorders, irritability, palpitations, dream-disturbed sleep and insomnia (Sinclair, 1998). The major chemical constituents of DDB are schizandrin, deoxyschizandrin, schisanhenol, schizandrol, sesquicarene, $\beta$ chamigrene, citral, stigmasterol and vitamins $\mathrm{C}$ and $\mathrm{E}$ (Hong, 1986; Bensky and Gamble 1993). It was reported that, DDB protects against carbon tetrachloride, D-galactosamine, and thioacetamide-induced hepatic injury (Yu et al., 1987). It lowers sGPT level in patients with chronic viral hepatitis and decrease the hepatotoxicity in animals with few side effects (Liu et al., 1978). A pharmacological study conducted by Li, 1991, showed that DDB increased liver protein and glycogen synthesis and had an inducing effect on the cytochrome P-450 enzyme system. Also, DDB was found to inhibit vitamin $\mathrm{C} /$ NADPH induced lipid peroxidation in rat liver microsomes and appear to be more effective than vitamin $\mathrm{E}$ at the same concentration. DDB formed a metabolite-P450 complex with P450 upon incubation with human liver microsomes in the presence of NADPH (Kim et al., 2001). P450s were demonstrated to be the primary enzymes responsible for the metabolism of DDB in human liver microsomes via demethylenation and by generating secondary metabolites (Baek et al., 2001). The aim of this work is to study and gain insight the biochemical effects exerted upon DDB treatment of tamoxifen-induced liver injury and lipid peroxidation.

\section{Materials and Methods}

Chemicals Dimethyl Dimethoxy Biphenyl Dicarboxylate (DDB) was received as a gift from Arab company for pharmaceuticals and medicinal plants (Mepaco), Egypt. Tamoxifen citrate was a kind gift obtained from medical union pharmaceutical drug company (MUP), Egypt. All the other chemicals were of analytical grade and purchased from Sigma (St. Louis, USA) and Fluka (Buchs, Switzerlands).

Animals Fifty adult female albino rats weighed 120-170 gm were used as experimental animals in this study. The animals were housed in the animal care centre of faculty of Pharmacy, Al-Azhar University. They were kept under identical conditions with free access to standard laboratory food (Purina Chow) and water.

Experimental Protocol The rats were randomly divided into 5 groups of 10 animals each as follows:-

- Group 1: Normal control untreated rats.

- Group 2: Tamoxifen-intoxicated rats: Rats were treated with tamoxifen citrate i.p.in a dose of $45 \mathrm{mg} / \mathrm{Kg}$ body weight in 0.1 $\mathrm{ml}$ dimethylsulfoxide (DMSO)/Kg body weight for 7 successive days (Hard et al., 1993).

- Group 3: DDB-treated rats: Rats were orally administered 200 $\mathrm{mg}$ DDB in $1 \mathrm{ml}$ tween $/ \mathrm{Kg}$ body weight daily for 10 successive days (Zohny et al., 2001).

- Group 4: DDB (P) rats: Rats were orally administered DDB (in a dose similar to group 3) prior tamoxifen intoxication as protection $(\mathrm{P})$ against liver injury induced by tamoxifen.

- Group 5: DDB (C) rats: Rats were orally administered DDB (in a dose similar to group 3) after tamoxifen intoxication as a curative (C) against liver injury induced by tamoxifen.

At the end of the experiment, animals were subjected to light ether anaesthesia and killed by cervical dislocation. The blood sample were collected in heparinised centrifuge tube and centrifuged to obtain serum. The abdomen was excised and the liver was removed immediately by dissection, washed in ice-cold isotonic saline and blotted between two filter papers. The liver was wrapped in aluminum foil and stored at $80^{\circ} \mathrm{C}$. A $10 \%(\mathrm{w} / \mathrm{v})$ liver homogenates was prepared in ice-cold $0.1 \mathrm{M}$ potassium phosphate buffer, PH 7.5 using Branson sonifier (250, VWR Scientific, USA).

Biochemical parameters Fresh aliquot from liver homogenate was used to estimate glutathione-S-transferase (Habig et al., 1974), glutathione peroxidase (Qi-chang et al., 1987), catalase (Clairborne, 
1985), reduced glutathione (Ellman, 1959) and thiobarbituric acid reactive substance (Ohkawa et al., 1979). However, serum was used to measure the level of sGPT and sGOT liver transaminases (White et al., 1970). The determination of sGOT and sGPT transaminases based on the fact that phenylhydrazone that produced after incubation the substrate with the enzyme, was measured spectrophotometrically. The amount of phenylhydrazone formed was directly proportional to the enzyme quantity.

The glutathione-S-transferase was determined spectrophotometrically using aromatic substrate (1-cholro-2,4 dinitrobenzene) and monitor the change in absorbance due to thioester formation. One unit of the enzyme is defined as the amount of glutathione-S-transferase which needed to catalyze the formation of $1 \mu \mathrm{mol}$ of thioester per minute and the specific activity is expressed as $\mathrm{nmol} / \mathrm{min} / \mathrm{mg}$ protein. The glutathione peroxidase was determined by reversed phase HPLC using LDC analytical system equipped with C18 econosil $5 \mu$ ODS $250 \times 4.6 \mathrm{~mm}$ column packed with $5 \mu$ particle size at flow rate $1 \mathrm{ml} / \mathrm{min}$. This procedure based on the fact that glutathione peroxidase converts the GSH (reduced glutathione) into GSSG (oxidized glutathione). The increase in GSSG amount is directly proportional to glutathione peroxidase activity and the specific activity is expressed as $\mathrm{U} / \mathrm{mg}$ protein. The catalase activity was measured using $\mathrm{H}_{2} \mathrm{O}_{2}$ as substrate that can be decomposed by catalase enzyme. One unit of catalase is defined as the amount needed to decompose $1 \mathrm{nmol} \mathrm{H}_{2} \mathrm{O}_{2}$ of per minute and the specific activity is expressed as $\mathrm{U} / \mathrm{mg}$ protein.

The reduced glutathione was measured spectrophotometrically using 5 ',5'dithiobis(2-nitrobenzoic acid), that was converted to 2nitro-S-mercaptobenzoic acid per one mole of glutathione. The amount of reduced glutathione is expressed as nmol/mg protein. The lipid peroxides expressed as nmol of thiobarbituric acid reactive substance (TBARS) production per mg protein was measured spectrophotometrically using 1,1,3,3-tetrathoxypropane.

Statistical analysis All data were expressed as mean \pm SEM. The standard error was calculated by dividing the standard deviation by the square root of the number of observations. Paired $t$-test was carried out to compare populations using GraphPad Prism software (San Diego, CA). Statistical significance was defined as a $\mathrm{p}$ value $<0.005$ and 0.01 .

\section{Results}

The administration of high dose tamoxifen citrate elicited dramatic increase in the activity of sGPT and sGOT liver transaminases. The Liver damage was evaluated by the measurement of serum level of GPT and GOT transaminases. Rats that orally administered DDB for 10 days, showed no significant change with the normal control group.

The pretreatment (protection) and treatment (curative) of tamoxifen-intoxicated rats with DDB significantly decreased sGPT and sGOT levels in comparing to the tamoxifeninduced liver injury group. The sGPT was significantly decreased by $\downarrow-61.0 \%$ and $\downarrow-50.0 \%$ for protected and curative group, respectively. While, the sGOT was significantly decreased by $\downarrow-50.0 \%$ and $\downarrow-35.0 \%$ for protected and curative
Table 1. The influence of oral administration of dimethyl dimethoxy biphenyl dicarboxylate (DDB) to normal rats and before (protective) and after (curative) tamoxifen citrate intoxication on serum GPT and serum GOT liver transaminases

\begin{tabular}{rcc}
\hline Animal Groups & $\begin{array}{c}\text { sGPT } \\
(\mathrm{U} / \mathrm{L})\end{array}$ & $\begin{array}{c}\text { sGOT } \\
(\mathrm{U} / \mathrm{L})\end{array}$ \\
\hline Normal Control & & \\
$\mathrm{M} \pm$ S.E. & $60 \pm 2.0$ & $30.2 \pm 0.2$ \\
Range & $50-66$ & $29.7-30.8$ \\
TAM-intoxicated & & \\
$\mathrm{M} \pm$ S.E. & $181 \pm 4.0^{\#}$ & $70 \pm 0.3^{\#}$ \\
Range & $160-209$ & $69.5-70.6$ \\
$\%$ Change & $\uparrow+300^{\#} \%$ & $\uparrow+132 \%$ \\
& & \\
DDB-treated & $59 \pm 2.0$ & $30 \pm 2.0$ \\
$\mathrm{M} \pm$ S.E. & $51-69$ & $27-32$ \\
Range & $\uparrow-2.0 \%$ & $\downarrow-0.30 \%$ \\
$\%$ Change & & $35 \pm 0.14 *$ \\
DDB (P) & $70 \pm 1.0 *$ & $32-42$ \\
M S.E. & $63-80$ & $\downarrow-50.0 * \%$ \\
Range & $\downarrow-61.0 * \%$ & \\
$\%$ Change & & $45 \pm 0.2^{*} *$ \\
DDB (C) & & $39-47$ \\
M S.E. & $90 \pm 2.0 *$ & $\downarrow-35.0 * \%$ \\
Range & $78-94$ &
\end{tabular}

DDB(P): protection group; $\mathbf{D D B}(\mathbf{C})$ : curative group; TAM: tamoxifen citrate.

Values are expressed as mean \pm S.E.

Number of rats per group $n=10$.

*Significance difference from TAM-intoxicated group at $p<0.005$.

${ }^{\#}$ Significance difference from normal control group at $p<0.005$.

group, respectively (Table 1).

The influence of tamoxifen citrate intoxication and DDB on the antioxidant enzyme activities (glutathione-S-transferase, GST; glutathione peroxidase, GPX and catalase, CAT), reduced glutathione (GSH) and thiobarbituric acid reactive substance (TBARS) of rats liver are showed in Table 2. The level of thiobarbituric acid reactive substance (TBARS) is an indicative for lipid peroxidation of hepatic cells. The tamoxifen-intoxication resulted in liver injury in rats as manifested by significant decline in GST, GPX, CAT and GSH enzyme levels by $\downarrow-26 \%, \downarrow-35.0 \%, \downarrow-41.0 \%$ and $\downarrow$ $27.0 \%$, respectively compared to the normal control. However, TBARS level showed a huge significant increase in tamoxifen-intoxicated rats by $\uparrow+2220 \%$ in comparing to the normal control group. The administration of DDB to normal rats resulted in significant increase of GST and GSH enzymes levels by $\uparrow+10.4 \%$ and $\uparrow+13.3 \%$, respectively. However the enzyme levels of GPX, CAT and TBARS showed non significant changes compared to the normal rats. On the other hand, the administration of DDB to normal rats resulted in non significant decrease in TBARS compared to normal control group (Table 2). 
Table 2. The pre-treatment (protection) and post-treatment (curative) effects of dimethyl dimethoxy biphenyl dicarboxylate (DDB) on antioxidant enzyme activities [glutathione-S-transferase, GST; glutathione peroxidase, GPX and catalase, CAT], reduced glutathione (GSH) and thiobarbituric acid reactive substance (TBARS) of tamoxifen-intoxicated rat liver homogenate

\begin{tabular}{|c|c|c|c|c|c|}
\hline Animal Groups & $\begin{array}{c}\text { GST } \\
\mathrm{nmol} / \mathrm{min} / \mathrm{mg} \text { protein }\end{array}$ & $\begin{array}{c}\text { GPX } \\
\text { U/mg protein }\end{array}$ & $\begin{array}{c}\text { CAT } \\
\mathrm{U} / \mathrm{mg} \text { protein }\end{array}$ & $\begin{array}{c}\mathrm{GSH} \\
\mathrm{nmol} / \mathrm{mg} \text { protein }\end{array}$ & $\begin{array}{c}\text { TBARS } \\
\mathrm{nmol} / \mathrm{mg} \text { protein }\end{array}$ \\
\hline \multicolumn{6}{|l|}{ Normal Control } \\
\hline $\begin{array}{r}\mathrm{M} \pm \text { S.E. } \\
\text { Range }\end{array}$ & $\begin{array}{c}270 \pm 7 \\
220-300\end{array}$ & $\begin{array}{c}26 \pm 1.5 \\
22-29\end{array}$ & $\begin{array}{c}36 \pm 2.0 \\
32-43\end{array}$ & $\begin{array}{l}30 \pm 2.0 \\
25.9-33\end{array}$ & $\begin{array}{c}0.9 \pm 0.1 \\
0.61 .2\end{array}$ \\
\hline $\begin{array}{r}\text { TAM-intoxicated rats } \\
\mathrm{M} \pm \text { S.E. } \\
\text { Range } \\
\% \text { Change }\end{array}$ & $\begin{array}{l}200 \pm 4.0^{\#} \\
180-235 \\
\downarrow-26.0^{\#} \%\end{array}$ & $\begin{array}{l}17 \pm 1.0^{\#} \\
13-20 \\
\downarrow-35.0^{\#} \%\end{array}$ & $\begin{array}{c}21 \pm 1.0^{\#} \\
18-24 \\
\downarrow-41.0^{\#} \%\end{array}$ & $\begin{array}{l}22 \pm 1.0^{\#} \\
20-25 \\
\downarrow-27.0^{\#} \%\end{array}$ & $\begin{array}{l}21 \pm 0.6^{\#} \\
18-24 \\
+2220^{\#} \%\end{array}$ \\
\hline $\begin{array}{r}\text { DDB- treated normal rats } \\
\mathrm{M} \pm \text { S.E. } \\
\text { Range } \\
\% \text { Change }\end{array}$ & $\begin{array}{l}298 \pm 5.0^{\#} \\
260-320 \\
\uparrow+10.0^{\# 0} \%\end{array}$ & $\begin{array}{c}27 \pm 1.0 \\
20-31 \\
\uparrow+4.0 \%\end{array}$ & $\begin{array}{l}39 \pm 1.0 \\
33-45 \\
\uparrow+8.0 \%\end{array}$ & $\begin{array}{c}34 \pm 0.4^{\#} \\
30-37 \\
\uparrow+13.3^{\#} \%\end{array}$ & $\begin{array}{c}0.8 \pm 0.01 \\
0.5-0.9 \\
\downarrow-11.00 \%\end{array}$ \\
\hline \multicolumn{6}{|l|}{ DDB (P) } \\
\hline $\begin{array}{r}\mathrm{M} \pm \mathrm{S} . \mathrm{E} . \\
\text { Range } \\
\% \text { Change }\end{array}$ & $\begin{array}{c}258 \pm 5.0 * \\
240-270 \\
\uparrow+29.0 * \%\end{array}$ & $\begin{array}{c}23 \pm 1.0 * \\
17-26 \\
\uparrow+35.0 * \%\end{array}$ & $\begin{array}{c}31 \pm 2.0^{*} \\
28-33 \\
\uparrow+48.0^{* \%} \%\end{array}$ & $\begin{array}{c}25 \pm 0.6^{*} \\
21-27 \\
\uparrow+14.0^{* \%} \%\end{array}$ & $\begin{array}{l}8.1 \pm 0.1^{*} \\
7.3-9.8 \\
\downarrow-61.0^{*} \%\end{array}$ \\
\hline \multicolumn{6}{|l|}{ DDB (C) } \\
\hline $\begin{array}{r}\mathrm{M} \pm \text { S.E. } \\
\text { Range } \\
\% \text { Change }\end{array}$ & $\begin{array}{c}240 \pm 5.0 * \\
230-252 \\
\uparrow+20.0 * \%\end{array}$ & $\begin{array}{c}20 \pm 0.9 * \\
16.3-22.8 \\
\uparrow+18.0 * \%\end{array}$ & $\begin{array}{c}25 \pm 0.8^{*} \\
21.4-28 \\
\uparrow+19.0^{* \%} \%\end{array}$ & $\begin{array}{c}23 \pm 0.7 \\
20-25 \\
\uparrow+5.0 \%\end{array}$ & $\begin{array}{c}12 \pm 0.5^{*} \\
9.8-14 \\
\downarrow-43.0 * \%\end{array}$ \\
\hline
\end{tabular}

DDB(P): protection group; DDB(C): curative group; TAM: tamoxifen citrate.

Values are expressed as mean \pm S.E.

Number of rats per group $\mathrm{n}=10$.

*Significance difference from TAM-intoxicated group at $p<0.01$.

\#Significance difference from normal control group at $p<0.005$.

Moreover, the pre-treatment or treatment with DDB (Table 2 ), improved the activities of antioxidant enzymes such as glutathione-S-transferase, glutathione peroxidase and catalase as well as the level of reduced glutathione and thiobarbituric acid reactive substance, in comparing to tamoxifen-intoxicated liver injured rats group.

The pretreatment of tamoxifen-intoxicated rats with DDB (Table 2) elicited the strongest effect in inducing a highly significant decline in TBARS and a highly significant increase in the activities of antioxidant enzymes and the level of reduced glutathione in comparison to tamoxifen-intoxicated rats. The results showed a significant increment in the levels of GST, GPX, CAT and GSH enzymes by $\uparrow+29 \%$, $\uparrow+35.0 \%$, $\uparrow+48.0 \%$ and $\uparrow+14.0 \%$, respectively compared to normal control. The administration of DDB prior to tamoxifenintoxication resulted in highly significant decrease TBARS by $\downarrow-61.0 \%$ level (Table 2 ).

The post-treatment (curative) of tamoxifen-intoxicated group with DDB i.e. DDB administered to rats after tamoxifen intoxication (Table 2) elicited a significant decline in TBARS and a significant increase in the activities of antioxidant enzymes and the level of reduced glutathione in comparison to the tamoxifen-intoxicated rats. The results showed a significant increment in the levels of GST, GPX, CAT and GSH enzymes by $\uparrow+20 \%, \uparrow+18.0 \%, \uparrow+19 \%$ and $\uparrow+5.0 \%$, respectively compared to the normal control. The administration of DDB after tamoxifen-intoxication resulted in significant decrease of TBARS level by $\downarrow-43.0 \%$ (Table 2 ).

\section{Discussion}

Tamoxifen citrate is an anti-estrogenic drug widely used for the treatment of breast cancer (Desai et al., 2002). It was obvious that tamoxifen in toxic doses lead to oxidative liver damage (Hard et al., 1993) as it have been elucidated to be a hepatocarcinogen in rats (Ahotupa et al., 1994; Karki et al., 2000). This study was conducted in order to investigate the role of DDB in alleviating the oxidative stress status obtained upon tamoxifen-intoxication in female rats that resulted in liver injury due to the involvement of oxidant mechanisms (Akcay et al., 2000). It was reported that, DDB have a strong scavenging effect against active oxygen radicals ( $\mathrm{Li}$ et al., 1990). Tamoxifen may be more toxic to the liver because it 
has much higher affinity for hepatic tissue than for any other tissues (Desai et al., 2002). It results in a shift toward the growth of diploid hepatocytes in rat liver cells (Dragon et al., 1998). Tamoxifen was found to produce five DNA adducts in rat liver that appeared to be responsible for carcinogenesis (Hemminki et al., 1995; Hellmann-Blumberg et al., 2000). In accordance with the data obtained from this study, Stanley et al., 2001, reported that tamoxifen administration resulted in significant increase in thiobarbituric acid reactive substance (TBARS) production. The lipid peroxidation may be attributed to the fact that hexose monophosphate shunt (HMP) in rat liver is strongly inhibited by high dose of tamoxifen, so that the NADPH levels inside cells is decreased. The state of oxidative stress observed during tamoxifen administration in high dose was accompanied by decreased hepatic glutathione content and increased peroxidation (Ahotupa et al., 1994). The activities of some intracellular antioxidant enzymes decreased with the increase of lipid peroxidation levels (Diplock et al., 1994) which was concomittent with the results achieved from this study.

The pre-treatment as well as treatment of tamoxifen intoxicated rats with DDB, inhibited the tamoxifen-induced hepatic injury and thereby the level of oxidative stress as it can decrease lipid peroxidation and enhance the antioxidant enzyme activities. The decrease in antioxidant defence systems in animals render them more susceptible to the hepatotoxcity (Palomero et al., 2001). The liver damage was determined by the measurement of sGOT and sGPT while the level of TBARS in liver was used as an indicative of lipid peroxidation. The levels of antioxidant enzyme activities in liver homogenates (glutathione-S-transferase, glutathione peroxidase and catalase) and reduced glutathione were significantly increased whereas the level of TBARS were significantly decreased comparable to tamoxifen-intoxicated group (Table 2). On the contrary, Oge et al., 2003, showed that catalase did not show any significant difference after tamoxifen intoxication.

In agreement with the results obtained in this study, Lu and Liu, 1991, reported that when DDB given orally to mice, there was significant reduction in TBARS formation with increased superoxide dismutase and catalase activity. Also, it was obvious that, DDB increased the concentration of nitric oxide and cortisol in blood plasma and saliva (Panossian et al., 1999) and improved the liver functions as the elevated serum GPT and GOT in liver hepatitis patients have been decreased (Liu, 1989). The pretreatment with DDB exerted a little more beneficiary improvements than its use as a treatment (curative) against tamoxifen-intoxication.

In conclusion, the present data indicate that the oral administration of DDB, have a beneficial effects on damaged liver cells to prevent lipid peroxidation and improve antioxidant enzyme activities of tamoxifen-intoxicated rats. Moreover, the use of DDB before tamoxifen treatment (as protection) is more effective than its curative effect (DDB administered after tamoxifen treatment) against tamoxifen- induced liver injury. The data obtained from this study revealed that DDB can mediate its biochemical effects through the enhancement of the antioxidant enzyme activities and reduced glutathione level as well as decreasing the level of lipid peroxides.

\section{References}

Akcay, T., Dinner, Y., Kayali, R., Colgar, U., Oral, E. and Cakatay, U. (2000) Effects of hormone replacement therapy on lipid peroxides and oxidation system in postmenopausal womwn. J. Toxicol. Environ. Health 59, 1-5.

Ali, S. and Coombes, R. C. (2002) Endocrine responsive breast cancer and strategies for combating resistance. Nat. Rev. Cancer 2, 101-112.

Atalay, G., Dirix, L., Biganzoli, L., Beex, L., Nooij, M., Cameron, D. and Lohrisch, C. (2004) The effect of exemestane on serum lipids profile in postmenopausal women with metastatic breast cancer. Ann. Oncol. 15, 211-217.

Athoupa, M., Hirsimaki, P., Parssinen, R. and Mantyla, E. (1994) Alterations of drug metabolizing and antioxidant enzyme activities during tamoxifen-induced hepatocarcinogenesis in rats. Carcinogenesis 15, 863-868.

Baek, M. S., Kim, J. Y., Myung, S. W., Yim, Y. H., Jeong, J. H. and Kim, D. H. (2001) Metabolism of DDB by human liver microsomal cytochrome P450: probable involvement of CYP3A and CYP1A2. Drug Metab. Dispos. 29, 381-388.

Bensky, D. and Gamble A. (1993) Traditional indications of DDB; in Chinese Herbal Medicine, Medica, M. (eds), pp. 110-112, Eastland Press, Seattle, USA.

Caballero, F., Gerez, E., Oliveri, L., Falcolff, N., Battle, A. and Vazquez, E. (2001) On the promoting action of tamoxifen in a model of hepatocarcinogenesis induced by p-dimethylaminobenzene in CF1 mice. Int. J. Biochem. Cell. Biol. 33, 681-690.

Clairborne, A. (1985) Catalase activity; in Handbook of Methods for Oxygen Radical Research, Greenwald, R. A. (ed.), p. 383, CRC press, Boca Raton, USA.

Dehal, S. S. and Kupfer, D. (1997) CYP2D6 catalyzes tamoxifen 4-hydroxylation in human liver, Cancer Res. 57, 3402-3406.

Dehal, S. S. and Kupfer, D. (1999) Cytochrome P450 3A and 2D6 catalyze ortho hydroxylation of 4-hydroxytamoxifen and 3-hydroxytamoxifen (droloxifene) yielding tamoxifen catechol: involvement of catechols in covalent binding to hepatic proteins. Drug Metab. Dispos. 27, 681-688.

Desai, P., Nallani, S., Sane, R., Moore, L., Goodwin, B., Buckley, D. and Buckley, A. (2002) Induction of Cytochrome P450 3A4 in Primary Human Hepatocytes and Activation of the Human Pregnane X Receptor by Tamoxifen and 4-Hydroxytamoxifen. Drug Metab. Dispos. 30, 608-612.

Diplock, A. T., Rice, C. A. and Burdon, R. H. (1994) Is there a significant role for lipid peroxidation in the causation of malignancy and for antioxidants in cancer prevention. Cancer. Res. 54, 1952-1956.

Dragon, Y. P., Xu, Y. D. and Pilot, H. C. (1998) Tumour promotion as a target for estrogen/antiestrogen effects in rat hepatocarcinogenesis. Prev. Med. 20, 15-26.

Ellman, G. L. (1959) Tissue sulfahydryl groups. Arch. Biochem. Biophys. 82, 70-77. 
Emile, F. N., Dragan, Y. P., Colin, R. J., Jordan, V. C. and Pitot, H. C. (1995) Effects of tamoxifen administration on the expression of xenobiotic metabolizing enzymes in rat liver. Cancer Res. 55, 1780-1786.

$\mathrm{Fu}$, T. and Liu, G. (1992) Protective effects of dimethyl-4,4' dimethoxy-5,6,5',6'-dimethylene dioxybiphenyl-2,2'-dicarboxylate on damages of isolated rat hepatocytes induced by carbon tetrachloride and D-galactosamine. Biomed. Environ. Sci. 5, 185-194.

Habig, W. H., Pabst, M. J. and Jakoby, W. B. (1974) GlutathioneS-transferases. The first enzymatic step in mercaptouric acid formation. J. Biol. Chem. 249, 7130-7139.

Han, Y. and Liehr, J. G. (1992) Induction of covalent DNA adducts in rodents by tamoxifen. Cancer Res. 52, 1360-1363.

Hard, G. C., Iatropoulos, M. J., Jordan, K., Kaltenberg, O. P., Imondi, A. R. and Williams, G. M. (1993) Major difference in the hepatocarcinogenecity and DNA adduct forming ability between toremifene and tamoxifen in female rats. Cancer Res. 53, 4534-4541.

Hellmann-Blumberg, U., Taras, T. L., Wurz, G. T. and DeGreorio, M. W. (2000) Genotoxic effects of the novel antiestrogenic FC1271a in comparison to tamoxifen and toremifene. Breast Cancer Res. Treat. 60, 63-70.

Hemminki, K., Widlak, P. and Hou, S. M. (1995) DNA adducts caused by tamoxifen and toremifene in human microsomal system and lymphocytes in vitro. Carcinogenesis 16, 16611664.

Hong, Y. H. (1986) Antibacterial effect of DDB; in Oriental Materia Medica: A Concise Guide, p. 65, Oriental Healing Arts Institute, Long Beach, USA.

Ip, S. P., Yiu, H. Y. and Ko, K. M. (2000) Differential effects of schisandrin $\mathrm{B}$ and dimethyl diphenyl bicarboxylate (DDB) on hepatic mitochondrial glutathione redox status in carbon tetrachloride intoxicated mice. Mol. Cell Biochem. 205, 111114.

Jordan, V. C. (2003) Tamoxifen: a most unlikely pioneering medicine. Natl. Rev. Drug. Discov. 2, 205-213.

Karki, A., Mantyla, E., Hirsimaki, Y., Karlsson, S., Toikkanen, S. and Hirsimaki, P. (2000) Comparison of the effects of tamoxifen and toremifene on rat hepatocarcinogenesis. Arch. Toxicol. 74, 249-256.

Kim, J., Baek, M., Lee, S., Kim, S., Dong, M., Kim, B. and Kim, D. (2001) Characterization of the Selectivity and Mechanism of Cytochrome P450 Inhibition by Dimethyl-4,4'-dimethoxy5,6,5',6'-dimethylenedioxybiphenyl-2,2'-dicarboxylate, Drug Metab. Dispos. 29, 1555-1560.

Kim, S. N., Kim, S. Y., Yim, S. Y., Lee, W. Y., Ham, K. S., Kim, S. K., Yoon, M. Y. and Kim, Y. C. (1999) Effect of dimethyl4,4'-dimethoxy-5,6,5',6'-dimethylene dioxybiphenyl-2,2'-dicarboxylate (DDB) on chemical induced liver injury. Biol. Pharm. Bull. 22, 93-95.

Kupfer, D., Mani, C., Lee, C. and Rifkind, A. (1994) Induction of tamoxifen-4-hydroxylation by 2,3,7,8-tetrachlorodibenzo-pdioxin (TCDD), beta-naphthoflavone (beta NF), and phenobarbital (PB) in avian liver: identification of $\mathrm{P} 450$ TCDDAA as catalyst of 4-hydroxylation induced by TCDD and beta NF. Cancer Res. 54, 3140-3144.

Letteron, P., Labbe, G., Degott, C., Berson, A., Fromenty, B., Delaforge, M., Larrey, D. and Pessayre, D. (1990) Mechanism for the protective effects of silymarin against carbon tetrachloride-induced lipid peroxidation and hepatotoxicity in mice. Evidence that silymarin acts both as an inhibitor of metabolic activation and as a chain-breaking antioxidant. Biochem. Pharmacol. 39, 2027-2034.

Li, X. J., Zhao, B. L., Liu, G. T. and Xin, W. J. (1990) Scavenging effects on active oxygen radicals by schizandrins with different structures and configurations. Free Radic. Biol. Med. 9, 99-104.

Li, X. Y. (1991) Bioactivity of neolignans from fructus Schizandrae. Mem. Inst. Oswaldo Cruz. 86, 31-37.

Liu, G. T. (1989) Pharmacological actions and clinical use of fructus Schizandrae. Chin. Med. J. 102, 740-749.

Liu, C. S., Fang, S. D., Huang, M. F., Kao, Y. L. and Hsu, J. S. (1978) Studies on the active principles of Schisandra sphenanthera Rehd. et Wils. The structures of schisantherin A, B, C, D, E, and the related compounds. Sci. Sin. 21, 483-502.

Liu, Z., Shi, H. Y., Nawaz, Z. and Zhang, M. (2004) Tamoxifen induces the expression of maspin through estrogen receptor alpha. Cancer Lett. 209, 55-65.

$\mathrm{Lu}, \mathrm{H}$. and Liu, G. T. (1991) Effect of dibenzo[a,c]cyclootene lignans isolated from fructus Schizandrae on lipid peroxidation and anti-oxidative enzyme activity. Chem. Biol. Interact. 78, 77-84.

McCay, P. B., Lai, E. K., Poyer, J. L., Dubose, C. M. and Janzen, E. C. (1984) Oxygen and carbon centered free radical formation during carbon tetrachloride metabolism. Observation of lipid radicals in vivo and in vitro. J. Biol. Chem. 259, 21352143.

Oge, A., Sezer, E. D., Ozgonul, M., Bayraktar, F. and Sozmen, E. Y. (2003) The effects of estrogen and raloxifene treatment on the antioxidant enzymes and nitrite-nitrate levels in brain cortex of ovarictomized rats. Neurosci. 338, 217-220.

Ohkawa, H., Ohishi, N. and Yagi, K. (1979) Assay for lipid peroxides in animal tissues by thiobarbituric reaction. Anal. Biochem. 95, 351-358.

Pagano, G., deBiase, A., Deeva, I. B., Degan, P., Doronin, Y. K., Iaccarino, M., Oral, R. and Korkina, L. G. (2001) The role of oxidative stress in development and reproductive toxicity of tamoxifen. Life Sci. 68, 1735-1749.

Palomero, J., Galan, A. I., Munoz, M. E., Tunon, M. J., GonzalezGallego, J. and Jimenez, R. (2001) Effects of aging on the susceptibility to the toxic effects of cyclosporine $\mathrm{A}$ in rats. Changes in liver glutathione and antioxidant enzymes. Free Rad. Biol. Med. 30, 836-845.

Panossian, A. G., Oganessian, A. S., Ambartsumian, M., Gabrielian, E. S., Wagner, H. and Wikman, G. (1999) Effects of heavy physical exercise and adaptogens on nitric oxide content in human saliva. Phytomedicine 9, 17-26.

Qi-Change, X., Lin, L., Degao, W. and Gen-Jun, X. (1987) Microassay of glutathione peroxidase by reduced phase HPLC. Chromatogram 9, 11-14.

Rosen, G. M., Britigan, B. E., Halpern, H. J. and Pou, S. (1999) Spin trapping free radicals in biological systems; in Free Radicals, Biology and Detection by Spin Trapping, p. 394, New York: Oxford Press, Oxford, United Kingdom.

Saarto, T., Blomqvist, C., Ehnholm, C., Taskinen, M. R. and Elomaa, I. (1996) Antiatherogenic effects of adjuvant antiestrogens: a randomized trial comparing the effects of tamoxifen on plasma lipid levels in postmenopausal women. $J$. Clin. Oncol. 14, 429-433. 
Simeone, A. M., Ekmikciolu, S., Grimm, E. A. and Tari, A. M. (2002) A novel mechanism by which retinamide inhibits breast cancer growth: the production of nitric oxide. Mol. Cancer Ther. 1, 1366.

Sinclair, S., (1998) Chinese herbs: a clinical review of astragalus, ligusticum, and schizandrae. Altern. Med. Rev. 3, 338-344.

Sridar, C., Kent, M., Notley, L., Gillam, E. and Hollenberg, P. (2002) Effect of Tamoxifen on the Enzymatic Activity of Human Cytochrome CYP2B6. Pharmacol. Exp. Therapeutics 301, 945-952.

Stanley, L. A., Carthew, P., Davies, R., Higginson, F., Martin, E. and Stayles, J. A. (2001) Delayed effects of tamoxifen in hepatocarcinogenesis. Cancer Lett. 171, 27.

Stefano, G. B., Cadet, P., Mantione, K., Cho, J. J., Jones, D. and Zhu, W. (2003) Estrogen signaling at the cell surface coupled to nitric oxide release in Mytilus edulis nervous system. Endocrinology 144, 1234-1240.

Williams, G. M., Iatropoulos, M. J., Djordjevic, M. V. and
Kaltenberg, O. P. (1993). The triphenylethylene drug tamoxifen is a strong liver carcinogen in the rat. Carcinogenesis 14, 315317.

White, B. A., Erickson, M. M. and Stevens, S. C. (1970) Determination of sGoT and sGPT enzymes; in Chemistry for Medical Technologists, pp. 293-296, Mosby, Saint Louis, USA.

Yu, F. L. and Bender, W. (2002) A proposed mechanism of tamoxifen in breast cancer prevention. Cancer Detect. Prev. 26, 370-375.

Yu, H. Q., Yang, X. U., Zang, Y. X. and Shi, J. Z. (1987) Biphenyl-dimethyl dicarboxylate in treating and preventing hepatitis due to drug poisoning. Chinese Med. J. Peking. 100, 122-123.

Zohny, S., Kandil, E., Moselhy, S. and Mohamed, E. (2001) Antioxidant properties of biphenyl dimethyl dicarboxylate, silymarin and garlic homogenates in carbon tetrachlorideinduced rat liver injury. Egy. J. Biochem. Mol. Biol. 20, 47-62. 